\title{
Primary needle-knife fistulotomy for preventing post- endoscopic retrograde cholangiopancreatography pancreatitis: importance of the endoscopist's expertise level
}

\section{Sung Yong Han}

Pusan National University Hospital https://orcid.org/0000-0002-0256-9781

\section{Dong Hoon Baek}

Pusan National University Hospital

Dong Uk Kim ( $\sim$ amlm3@hanmail.net )

Chang Joon Park

Pusan National University Hospital

\section{In Sub Han}

Pusan National University Hospital

\section{Gwang Ha Kim}

Pusan National University Hospital

\section{Geun Am Song}

Pusan National University Hospital

\section{Research article}

Keywords: Needle-knife fistulotomy, primary biliary cannulation, endoscopic retrograde cholangiopancreatography, expertise levels, pancreatitis

Posted Date: February 17th, 2020

DOI: https://doi.org/10.21203/rs.2.23737/v1

License: (c) (i) This work is licensed under a Creative Commons Attribution 4.0 International License. Read Full License

Version of Record: A version of this preprint was published at World Journal of Clinical Cases on June 16th, 2021. See the published version at https://doi.org/10.12998/wjcc.v9.i17.4166. 


\section{Abstract}

Background Needle-knife fistulotomy (NKF) is used as a rescue technique for difficult cannulation. However, the data are limited regarding the use of needle-knife fistulotomy for primary biliary cannulation, especially when performed by beginners. To assess the effectiveness and safety of primary NKF for biliary cannulation, and the role of the endoscopist's expertise level (beginner vs. expert).

Methods We retrospectively evaluated the records of 613 patients with naïve papilla and no history of pancreatitis, who underwent bile duct cannulation at a tertiary referral center. The patients were categorized according to the endoscopist's expertise level and the technique used for bile duct cannulation. We assessed the rates of successful cannulation and adverse events.

Results The baseline characteristics did not differ between the pre-defined groups. The incidence rate of post-endoscopic retrograde cholangiopancreatography (ERCP) pancreatitis (PEP) was significantly affected by the endoscopist's expertise level in patients who received conventional cannulation with sphincterotomy ( $11.3 \%$ vs. $5.7 \%$ for beginner vs. expert, $P=0.033$ ), but not in those who received NKF. In the multivariable analysis, a lower expertise level of the biliary endoscopist and longer cannulation time were significant risk factor of post-endoscopic retrograde cholangiopancreatography pancreatitis ( $P$ $=0.030, P=0.005)$ in patients who received conventional cannulation with sphincterotomy but not in those who received NKF.

Conclusion Compared to conventional cannulation with sphincterotomy, primary NKF carries a lower risk of PEP regardless of the endoscopist's level of expertise. Primary NKF may be effective and safe in achieving ductal access in patients with naïve papilla.

\section{Background}

Needle-knife fistulotomy (NKF) is used as a rescue technique when cannulation is difficult.[1] Many studies have reported the effectiveness and safety of early precut NKF for preventing post-endoscopic retrograde cholangiopancreatography (ERCP) pancreatitis (PEP). In particular, precut NKF was reported to be associated with a higher rate of successful cannulation and lower incidence of PEP than conventional cannulation techniques. $[2,3,4,5,6]$ Recently, randomized controlled trial study on NKF has been published, proved the safety and efficacy of primary NKF in high-risk cohort of PEP.[7] Despite these encouraging reports, NKF has not been adopted as a primary cannulation technique because most endoscopists believe that a high level of experience is required in order to achieve a sufficiently high rate of successful cannulation and an acceptable rate of adverse events in patients with naïve papilla. Several previous studies on the effectiveness and safety of early NKF reported that NKF procedures performed by less experienced or experienced endoscopists provided comparable rates of adverse events.[8, 9] However, there are no published data regarding the level of expertise that is needed for achieving the effectiveness and safety of NKF for primary biliary cannulation. The beginner endoscopist usually requires to perform more than 300 supervised procedures for achieving $80 \%$ of successful biliary cannulation using 
conventional methods. More experience may be necessary to achieve acceptable of success and adverse event with primary NFK.

It is of utmost importance to minimize the risk of PEP, which is difficult to control and potentially lethal even in cases handled by expert biliary endoscopists. Other life-threatening adverse events related to NKF, such as perforation and bleeding, have become relatively manageable due to the continuous developments in instrumentation (especially covered metalic stent, endoclips and absorbable hemostatic powder) and radiologic interventions (e.g., angiographic embolization). Therefore, it is necessary to determine the effectiveness and safety of NKF for primary biliary cannulation performed by beginners compared to those of experts. Furthermore, to our knowledge, there are only few study about that the effectiveness and safety of primary NKF for achieving bile duct access in patients with naïve papilla.[10]

We aimed to assess the effectiveness and safety of primary NKF in patients with naïve papilla undergoing bile duct cannulation and determine the role of the endoscopist's expertise level.

\section{Methods}

\section{Patient selection and stratification}

Among the patients who received ERCP at our hospital, we identified 568 patients who were managed by an expert (DUK; $>3,000$ ERCP procedures) as well as 596 patients managed by a beginner (DHB; $>300$ supervised ERCP procedures and no independent ERCP procedures at baseline of our study) between April 2014 and March 2016. The beginner was trained by the expert for a year prior to dispatch. We retrospectively reviewed the medical records of candidates and excluded patients who underwent previous ERCP or presented with biliary pancreatitis at admission. Finally, 613 patients with naïve papilla (expert, 301; beginner, 312) were enrolled in this study to analyze the effectiveness and safety of primary biliary cannulation, as well as to clarify the role of the endoscopist's expertise level (Figure 1). This study was conducted in accordance with the ethical guidelines of the Declaration of Helsinki (revised in 2013) and the study protocol was approved by the institutional review board of Pusan National University Hospital $(\mathrm{H}-$ 1805-023-067).

The patients were stratified according to the endoscopist's expertise level (beginner vs. expert) and according to the primary cannulation technique employed (conventional cannulation vs. NKF). Among the 301 patients managed by the expert, 211 underwent conventional cannulation using a guidewire-assisted technique, while 90 underwent NKF. Among the 312 patients managed by the beginner, 247 received conventional cannulation and 65 received NKF.

\section{Procedures}

Conventional cannulation was conducted by using a guidewire-assisted technique with various guidewires (Jagwire from Boston scientific, MA, USA; Terumo from Olympus Co., Tokyo, Japan; and Visiglide from Olympus Co.). The catheter impacts in the papilla before attempting to advance the guidewire for cannulation. When the expert was performing the procedure, the guidewire was initially manipulated by 
less-skillful assistants under training course. However, the beginner was accompanied by skillful assistants during the entire duration of conventional cannulation. If the ampullary orifice was probed $>5$ times or $>5$ minutes had passed without achieving biliary access, we switched to another technique such as pancreatic guidewire-assisted biliary cannulation, pancreatic duct stent placement followed by precut sphincterotomy, or NKF. However, as the study was retrospective in design, the time taken to change to the rescue method was not exactly equal in all cases but was constant. Prophylactic pancreatic stenting was attempted when there was pancreatic duct contrast injection or over twice of pancreatic duct cannulations. Sphincterotomy was performed in all patients. Patients who were performed ERCP without sphincterotomy were not enrolled. In precut sphincterotomy, the needle-knfie (Boston scientific, MA, USA) was initially placed at the orifice of the ampulla and the incision was made in an upward direction between the 11 and 12 o'clock positions. In precut NKF, the orifice of the ampulla of Vater remained without contact. The needle-knife as used to initially make a mucosal incision at the maximal bulging point of the papillary roof of the ampulla and then cut the oral side of papillary muscle at the 11-12 o'clock position (Figure 2). In order to reduce the risk of perforation, the needle was kept short with minimal incision of papillary muscles until the red mucosa of bile duct or bile was visualized. After biliary cannulations, additional sphincterotomy was not required for biliary stenting after biopsy or small stone removal, but additional sphincterotomy or endoscopic balloon dilatation was required to remove large stones.

\section{Outcome measures}

We evaluated the initial and final cannulation success rates, cannulation time, total procedure time, and ERCP-related adverse events in each group (expert vs. beginner; conventional cannulation with sphincterotomy vs. NKF). The effectiveness and safety of NKF for primary biliary cannulation were established based on the outcomes noted in patients managed by the expert.

Procedural success was defined as selective cannulation in a single ERCP session. Cannulation time was calculated from the first probing of the ampullary orifice until selective bile duct cannulation. Total procedure time was calculated from the first probing of the ampullary orifice until the end of the procedure. Our institution has some rules that during the ERCP procedure, we must capture the photo (confirmation of ampulla, after succeeding of cannulation, end of procedure). These pictures can be used to estimate cannulation time and total procedure time.

We monitored for PEP by measuring serum amylase and lipase levels before and at 24 hours after the procedure. Abdominal radiography was performed to check for perforation 4 hours after the procedure in patients with abdominal pain after procedure. ERCP-related adverse events were defined as bleeding, PEP, and perforation, the severity of which was classified according to the Cotton criteria.[11] Hyperamylasemia was defined as high amylase levels without abdominal pain or signs of pancreatitis.

Non-prominent ampulla was defined as a small papilla without marked oral protrusion. And bulging of the ampulla was defined as a marked swelling from the bulge in the papillary roof to the oral ridge of the duodenal wall [12]. The information that were including procedure method, outcome parameter were retrospectively reviewed by a third biliary endoscopist. 


\section{Statistical analysis}

Statistical analysis was performed using IBM SPSS statistical software, version 21.0 (IBM Corp, Armonk, NY). Baseline characteristics, procedural characteristics, and outcomes were compared between the groups that were defined based on the endoscopist's expertise level (expert vs. beginner) and cannulation technique (conventional cannulation vs. NKF). Univariate and multivariate analyses were conducted to identify the predictors of PEP. In the multivariate analysis, a p-value $<0.2$ in the univariate analysis was included and clinically and/or clinically meaningful variables were used. Statistical significance was considered for $P$-value below 0.05 .

\section{Results}

\section{Baseline characteristics}

The demographic and clinical characteristics of the 613 patients included in the study are summarized in Table 1. The two groups defined based on the endoscopist's expertise level did not differ significantly in terms of age, sex, ampullary morphology (e.g., periampullary diverticulum, ampulla configutations), or disease entity. The mean age of the patients was $67.0 \pm 13.8$ years, with a male predominance $(58.6 \%)$. Among the 613 patients enrolled, 221 (36.1\%) had malignancy. With respect to the ampullary morphology, 199 patients (32.5\%) had a periampullary diverticulum, 139 (22.7\%) had an non-prominent ampulla, and 50 (8.2\%) had bulging. In total, 221 patients underwent ERCP due to malignant biliary obstruction (36.1\%), of them underwent biliary drainage. Among the patients managed by the expert, those who underwent NKF were younger and more likely to exhibit bulging ampullary morphology than those who underwent conventional cannulation with sphincterotomy ( $68.2 \pm 12.6$ vs. $63.1 \pm 15.6$ years, $P=0.003 ; 3.8 \%$ vs. $18.9 \%$, $P=0.000$; respectively; Table 2).

\section{Relationship between expertise level and outcomes of different techniques}

The results of the comparison between the groups defined according to the endoscopist's expertise level are summarized in Table 3. Among the patients who underwent NKF, the expertise level was not associated with any significant differences in outcomes, including PEP incidence rate, procedural success rate, and cannulation time. However, among patients who underwent conventional cannulation with sphincterotomy, the PEP rate was significantly lower in patients managed by the expert than in those managed by the beginner ( $5.7 \%$ vs. $11.3 \%, P=0.033)$. Generally, the incidence rate of adverse events (PEP, hyperamylasemia, or bleeding) was lower among patients managed by the expert.

\section{Outcomes of conventional cannulation with sphincterotomy versus NKF performed by the expert}

The results of the comparison between conventional cannulation with sphincterotomy and NKF performed by the expert are summarized in Table 4 . The final success rate and the rate of post-ERCP bleeding or perforation did not differ between conventional cannulation and NKF. However, the cannulation time was 
significantly longer for conventional cannulation (7.2 min vs. $5.1 \mathrm{~min}, P=0.016)$. The incidence rate of PEP was higher for conventional cannulation with sphincterotomy (5.7\% vs. $1.1 \%, P=0.074)$, as was the incidence rate of hyperamylasemia ( $14.7 \%$ vs. $5.6 \%, P=0.025)$.

Among the 211 patients who underwent conventional cannulation performed by the expert, the initial success rate was $60.2 \%$ (127 patients). After switching to another technique, the bile duct could be accessed in 207 patients (final success rate, 98.1\%). Pancreatic duct stent with precut sphincterotomy was performed in 44 patients as a rescue method, needle knife fistulotomy in 21 patients, and double guidewire technique in 21 patients (Figure 1a.). The remaining 4 patients received percutaneous transhepatic biliary drainage. Among the 90 patients who received primary NKF performed by the expert, selective cannulation of the bile duct was achieved in 88 patients. Of the remaining 2 patients, one received pancreatic stentassisted precut sphincterotomy and the other percutaneous transhepatic biliary drainage.

Cannulation time, total procedure time, and bleeding rate did not significantly differ between conventional cannulation and NKF. However, the rates of PEP ( $7.1 \%$ vs. $1.1 \%, P=0.042)$ and hyperamylasemia $(15.0 \%$ vs. $5.7 \%, P=0.026)$ were significantly higher for conventional cannulation than for NKF, despite procedural success (Table 5). Paradoxically, for conventional cannulation, the incidence rate of PEP was lower in patients with procedural failure than in those with procedural success, though the difference was not significant (3.6\% vs. $7.1 \%, P=0.222)$.

\section{Clinical factors associated with PEP incidence}

Among the 613 patients with naïve papilla who underwent ERCP and presented with no pancreatitis at admission, a total of 43 developed PEP. In the univariate analysis, the endoscopist's expertise level was significantly associated with PEP incidence in patients who underwent conventional cannulation, whereas the cannulation time and total procedure time were significantly associated with PEP incidence in patients who underwent NKF. In the multivariate analysis, the endoscopist's expertise level $(P=0.030)$ and cannulation time $(P=0.005)$ were the independent predictor significantly associated with PEP incidence in patients who underwent conventional cannulation, whereas a longer total procedure time $(P=0.009)$ was associated with PEP occurrence in patients who underwent NKF (Table 6).

\section{Discussion}

Early NKF has been confirmed as a highly successful rescue procedure in cases with difficult bile duct access, being associated with low PEP incidence. $[9,13,14,15]$ Furthermore, it has been observed that the incidence rates of severe bleeding and perforation are similar between NKF and conventional cannulation with sphincterotomy. However, primary NKF continues to be considered a high-risk procedure in patients with naïve papilla. 
In our study, the incidence rate of PEP was significantly higher in patients managed by the beginner than in those managed by the expert endoscopist, although there was no significant difference in the final rate of successful cannulation. However, PEP incidence was lower for primary NKF than for conventional cannulation with sphincterotomy even when the procedure was performed by the beginner. Furthermore, the endoscopist's expertise level did not influence the PEP rate in patients who received NKF. Few studies have been published regarding the impact of the endoscopist's experience level on NKF outcomes. Lee et al.[9] reported that an endoscopist with experience of $>100$ ERCPs, including $>10$ precut procedures, can perform NKF efficiently and safely. In our study, the beginner had performed $>300$ supervised ERCP procedures but no independent procedures before starting this study. Based on the European guidelines regarding papillary cannulation,[16] NKF should be performed only by endoscopists who achieve successful biliary cannulation in $>80 \%$ of cases. A single-operator learning curve analysis for biliary cannulation suggested that procedural success rates of $>80 \%$ can be obtained after $>350$ supervised ERCP procedures.[17] Taken together, these previous findings and our present results suggest that it is acceptable to perform NKF after $>300$ supervised ERCP procedures.

In our study, the incidence rates of PEP $(5.7 \%$ vs. $1.1 \%, P=0.074)$ and hyperamylasemia $(14.7 \%$ vs. $5.6 \%, P$ $=0.025$ ) was significantly lower in patients who received NKF than in those who received conventional cannulation, even though the rates of other serious adverse events did not differ. A recent study reported that in comparison to delayed NKF, early NKF was associated with a significantly lower PEP incidence.[1] When cannulation is difficult, PEP probably occurs due to injury to the ductal orifice rather than due to the delayed NKF itself,[18] thus suggesting that early NKF helps minimize interaction with the pancreatic duct. However, the same recent study[1] concluded that primary precut NKF is not recommended in ERCP practice because conventional cannulation is highly successful in accessing the common bile duct. NKF has been criticized as potentially unsafe to be used as a primary cannulation technique. Nevertheless, we could not determine any specific situation in which PEP might occur. Many studies have confirmed that NKF is as safe as conventional cannulation techniques. $[9,13,14,15]$ Moreover, NKF helps minimize interaction with the pancreatic duct, whereas conventional techniques may cause PEP due to pancreatic duct irritation. A previous study reported that primary NKF was not associated with PEP. [8] However, when a deep incision is made through the needle, the pancreatic duct may be damaged. Moreover, some patients have long common channel of pancreatico-biliary junction that are covered with ampullary muscle. In such cases, the pancreatic duct may be damaged by primary NKF. Therefore, PEP may occur in some patients despite undergoing primary NKF. In case of pancreatic duct cannulation via primary NKF, a pancreatic duct stent was not used, which may be a potential cause of PEP in primary NKF. However, the PEP rate was significantly lower in NKF despite the level of the endoscopist's expertise. Finally, we did not find any other serious adverse events in patients who received NKF. Therefore, we recommend primary NKF as a good alternative technique for preventing PEP occurrence.

In our study, the final success rate of biliary cannulation was very high (98\%) in all groups; however, the cannulation time was longer for conventional techniques than for NKF (7.2 min vs. $5.1 \mathrm{~min}, \mathrm{P}=0.016)$. NKF requires time for making the mucosal incision, examining the ampulla, and creating the fistula. For this reason, in patients with successful cannulation, the cannulation time was slightly longer for NKF than 
for conventional cannulation ( 5.0 min vs. $3.9 \mathrm{~min}, \mathrm{P}=0.120$ ). The total procedure time did not differ with the cannulation technique. Furthermore, after excluding the cannulation time from the total procedure time, the ERCP time was also not affected by cannulation procedure.

Among patients who received conventional cannulation, PEP incidence was relatively lower for failed primary procedures that were switched to another technique than for successful primary procedures with bile duct access. We think that it was because a plastic stent was placed into the pancreatic duct if conventional cannulation failed to achieve bile duct access. A pancreatic stenting was reported to lower the PEP risk.[19, 20, 21] Therefore, the rate of hyperamylasemia did not differ between successful and failed primary procedures, whereas PEP incidence was lower in failed cases which the pancreatic stent was placed in.

We had no standard criteria for the selection of the cannulation technique. However, the morphology of the infundibulum was an important factor in the decision to try primary NKF. Specifically, if the infundibulum is large and covers the papilla, it is difficult to approach the ampullary orifice, and thus, NKF is expected to provide better results because it facilitates access to the bile duct at a site distinct from the ampullary orifice. The expert (DUK) frequently performed primary NKF procedures in patients who had large infundibula. If the patients had a small ampulla without an infundibulum, primary NKF was not performed. If the infundibulum extended beyond the field of view, a catheter was used to remove the air from the duodenum and probe the duodenal wall in order to evaluate the extent of the infundibulum. If a retracted ampulla or small ampulla was identified, conventional methods were used instead of NKF. In such ampulla, NKF is not considered suitable due to complications such as perforation. Primary NKF was preferred in patients with PEP risk factors such as non-dilated bile duct $(<9 \mathrm{~mm})$,[18] low serum levels of total bilirubin, and young age, which is why the age was lower in patients who received NKF than in those who received conventional cannulation. Additionally, one of the causes is the skill level of assistants; some assistants were skillful, but other assistants were not amenable to manipulation of the guidewire for biliary access. Therefore, the expert preferred performing primary NKF with unskillful assistants.

Our study has several limitations. First, this was a retrospective study, and the effect of selection bias could not be excluded. Second, the number of NKF procedures performed by the beginner was not uniformly distributed along the study period. Moreover, the PEP incidence was higher in the first half of the study period, when the beginner performed mostly conventional cannulation with sphincterotomy. Third, different assistants accompanied the two biliary endoscopists while performing the procedures. In the present analysis, we did not account for the fact that the skill of the assistants likely improved with time.

\section{Conclusions}

On the other hand, the present study enrolled a relatively large cohort of patients who received primary NKF. Furthermore, to the best of our knowledge, this is the first study to analyze the outcomes of primary NKF according to the endoscopist's expertise level. Our findings suggest that primary NKF is associated with reduced PEP risk regardless of the endoscopist's expertise level, which is very encouraging. Moreover, we confirmed that, when performed by an expert, primary NKF and conventional cannulation with 
sphincterotomy presents comparable rates of other adverse events such as bleeding and perforation. Therefore, we recommend primary NKF as an effective and safe method for achieving ductal access in patients with naïve papilla, and may be especially useful for beginners because, compared to conventional cannulation with sphincterotomy, NKF is less likely to induce PEP due to insufficient expertise of the endoscopist. Further prospective studies are warranted to validate our present results.

\section{Abbreviations}

Needle knife fistulotomy (NKF), Endoscopic retrograde cholangio-pancreatography (ERCP), Postendoscopic retrograde cholagniopancreatography pancreatitis (PEP)

\section{Declarations}

Ethics approval and consent to participate: This study was approved by the institutional review board of Pusan National University Hospital (H-1805-023-067). The institutional review board has approved the waiver of participation consent due to retroactive study.

Consent to publish: Not applicable.

Availability of data and materials: The raw data generated and analyzed in the current study are not publicly available due to appropriate protection of patient personal information.

Competing interests: The authors declare that they have no competing interests.

Funding: This study was supported by Biomedical Research Institute Grant (2018B035), Pusan National University Hospital

\section{Author's contributions:}

Study concept and design; Dong Uk Kim, Gwang Ha Kim

Data acquisition; Chang Joon Park, In Sub Han

Data analysis and interpretation; Sung Yong Han, Dong Hoon Baek

Drafting of the manuscript; Sung Yong Han, Dong Hoon Baek

Critical revision of the manuscript; Dong Uk Kim, Geun Am Song

Acknowledgements: not applicable 


\section{References}

1. Mariani A, Di Leo M, Giardullo N, Giussani A, Marini M, Buffoli F, Cipolletta L, Radaelli F, Ravelli P, Lombardi $\mathrm{G}$ et al: Early precut sphincterotomy for difficult biliary access to reduce post-ERCP pancreatitis: a randomized trial. Endoscopy 2016.

2. Chen J, Wan JH, Wu DY, Shu WQ, Xia L, Lu NH: Assessing Quality of Precut Sphincterotomy in Patients With Difficult Biliary Access. Journal of clinical gastroenterology 2018, 52(7):573-578.

3. Tang Z, Yang Y, Yang Z, Meng W, Li X: Early precut sphincterotomy does not increase the risk of adverse events for patients with difficult biliary access: A systematic review of randomized clinical trials with meta-analysis and trial sequential analysis. Medicine 2018, 97(36).

4. Sundaralingam P, Masson P, Bourke MJ: Early precut sphincterotomy does not increase risk during endoscopic retrograde cholangiopancreatography in patients with difficult biliary access: a metaanalysis of randomized controlled trials. Clinical Gastroenterology and Hepatology 2015, 13(10):17221729. e1722.

5. Navaneethan U, Konjeti R, Venkatesh PG, Sanaka MR, Parsi MA: Early precut sphincterotomy and the risk of endoscopic retrograde cholangiopancreatography related complications: an updated metaanalysis. World journal of gastrointestinal endoscopy 2014, 6(5):200.

6. Cennamo V, Fuccio L, Zagari R, Eusebi L, Ceroni L, Laterza L, Fabbri C, Bazzoli F: Can early precut implementation reduce endoscopic retrograde cholangiopancreatography-related complication risk? Meta-analysis of randomized controlled trials. Endoscopy 2010, 42(05):381-388.

7. Jang SI, Kim DU, Jeong S, Park J-S, Lee DH, Cho JH, Kwon C-I, Koh DH, Park SW, Lee TH: Primary Needle-Knife Fistulotomy versus Conventional Cannulation Method in High Risk Cohort of PostEndoscopic Retrograde Cholangiopancreatography Pancreatitis: A Multicenter Randomized Controlled Trial. Am J Gastroenterol 2020 Jan 07 doi: 1014309/ajg0000000000000480[Epub ahead of print] 2019.

8. Jin Y-J, Jeong S, Lee DH: Utility of needle-knife fistulotomy as an initial method of biliary cannulation to prevent post-ERCP pancreatitis in a highly selected at-risk group: a single-arm prospective feasibility study. Gastrointest Endosc 2016, 84(5):808-813.

9. Lee TH, Bang BW, Park S-H, Jeong S, Lee DH, Kim S-J: Precut fistulotomy for difficult biliary cannulation: is it a risky preference in relation to the experience of an endoscopist? Digest Dis Sci 2011, 56(6):1896-1903.

10. Khatibian M, SOTOUDEH M, ALI AA, Movahedi Z, KOLAH DS: Needle-knife fistulotomy versus standard method for cannulation of common bile duct: a randomized controlled trial. 2008.

11. Cotton PB, Lehman G, Vennes J, Geenen JE, Russell RC, Meyers WC, Liguory C, Nickl N: Endoscopic sphincterotomy complications and their management: an attempt at consensus. Gastrointest Endosc 
1991, 37(3):383-393.

12. Lee TH, Park S-H, Yang JK, Han SJ, Park S, Choi HJ, Lee YN, Cha S-W, Moon JH, Cho YD: Is the Isolated-Tip Needle-Knife Precut as Effective as Conventional Precut Fistulotomy in Difficult Biliary Cannulation? Gut Liver 2018, 12(5):597.

13. Freeman ML, Guda NM: ERCP cannulation: a review of reported techniques. Gastrointest Endosc 2005, 61(1):112-125.

14. Gong B, Hao L, Bie L, Sun B, Wang M: Does precut technique improve selective bile duct cannulation or increase post-ERCP pancreatitis rate? A meta-analysis of randomized controlled trials. Surg EndosC 2010, 24(11):2670-2680.

15. Kaffes AJ, Sriram PV, Rao GV, Santosh D, Reddy DN: Early institution of pre-cutting for difficult biliary cannulation: a prospective study comparing conventional vs. a modified technique. Gastrointest Endosc 2005, 62(5):669-674.

16. Testoni PA, Mariani A, Aabakken L, Arvanitakis M, Bories E, Costamagna G, Devière J, Dinis-Ribeiro M, Dumonceau J-M, Giovannini M: Papillary cannulation and sphincterotomy techniques at ERCP: European Society of Gastrointestinal Endoscopy (ESGE) clinical guideline. Endoscopy 2016, 48(07):657-683.

17. Verma D, Gostout CJ, Petersen BT, Levy MJ, Baron TH, Adler DG: Establishing a true assessment of endoscopic competence in ERCP during training and beyond: a single-operator learning curve for deep biliary cannulation in patients with native papillary anatomy. Gastrointest Endosc 2007, 65(3):394400.

18. Dumonceau JM, Andriulli A, Elmunzer BJ, Mariani A, Meister T, Deviere J, Marek T, Baron TH, Hassan C, Testoni PA et al: Prophylaxis of post-ERCP pancreatitis: European Society of Gastrointestinal Endoscopy (ESGE) Guideline - updated June 2014. Endoscopy 2014, 46(9):799-815.

19. Aizawa T, Ueno N: Stent placement in the pancreatic duct prevents pancreatitis after endoscopic sphincter dilation for removal of bile duct stones. Gastrointest Endosc 2001, 54(2):209-213.

20. Freeman ML, DiSario JA, Nelson DB, Fennerty MB, Lee JG, Bjorkman DJ, Overby CS, Aas J, Ryan ME, Bochna GS: Risk factors for post-ERCP pancreatitis: a prospective, multicenter study. Gastrointest Endosc 2001, 54(4):425-434.

21. Singh P, Das A, Isenberg G, Wong RC, Sivak MV, Agrawal D, Chak A: Does prophylactic pancreatic stent placement reduce the risk of post-ERCP acute pancreatitis? A meta-analysis of controlled trials. Gastrointest Endosc 2004, 60(4):544-550.

\section{Tables}

Table 1. Baseline characteristics between the expert and beginner endoscopists 


\begin{tabular}{lcccc}
\hline & Total & Expert & Beginner & $P$ value \\
& $\mathrm{N}=613,(\%)$ & $\mathrm{N}=301,(\%)$ & $\mathrm{N}=312,(\%)$ & \\
\hline Age (years) & $67.0 \pm 13.8$ & $66.7 \pm 13.7$ & $67.3 \pm 13.8$ & 0.591 \\
Male (\%) & $359(58.6)$ & $167(55.5)$ & $192(61.5)$ & 0.128 \\
Periampullary diverticulum & $199(32.5)$ & $104(34.6)$ & $95(30.4)$ & 0.279 \\
Ampulla configurations & & & & 0.877 \\
Non-prominent & $139(22.7)$ & $64(21.3)$ & $75(24.0)$ & \\
Prominent & $403(65.7)$ & $205(68.1)$ & $198(63.5)$ & \\
Bulging & $50(8.2)$ & $25(8.3)$ & $25(8.0)$ & \\
Distorted & $14(2.3)$ & $3(1.0)$ & $11(3.5)$ & \\
Hook-nose shape & $7(1.1)$ & $4(1.3)$ & $3(1.0)$ & \\
Malignancy & $221(36.1)$ & $110(36.5)$ & $111(35.6)$ & 0.803 \\
Benign diseases & $392(63.9)$ & $191(63.5)$ & $201(64.4)$ & \\
\hline
\end{tabular}

Table 2. Baseline characteristics between the conventional technique with sphincterotomy and NKF groups

\begin{tabular}{|c|c|c|c|c|c|c|c|c|}
\hline & \multicolumn{4}{|c|}{ Expert $\mathrm{N}=301,(\%)$} & \multicolumn{4}{|c|}{ Beginner $\mathrm{N}=312,(\%)$} \\
\hline & $\begin{array}{c}\text { Total } \\
\mathrm{N}=301, \\
(\%)\end{array}$ & $\begin{array}{l}\text { Conventional } \\
\text { technique with } \\
\text { sphincterotomy } \\
\mathrm{N}=211,(\%)\end{array}$ & $\begin{array}{c}\mathrm{NKF} \\
\mathrm{N}=90, \\
(\%)\end{array}$ & $P$ value & $\begin{array}{c}\text { Total } \\
\mathrm{N}=312, \\
(\%)\end{array}$ & $\begin{array}{r}\text { Conventional } \\
\text { technique with } \\
\text { sphincterotomy } \\
\mathrm{N}=247,(\%)\end{array}$ & $\begin{array}{c}\mathrm{NKF} \\
\mathrm{N}=65, \\
(\%)\end{array}$ & $P$ value \\
\hline Age (years) & $66.6 \pm 13.7$ & $68.2 \pm 12.6$ & $63.1 \pm 15.6$ & $0.003 *$ & $67.3 \pm 13.8$ & $67.0 \pm 13.4$ & $68.4 \pm 15.2$ & 0.462 \\
\hline Male & $167(55.5)$ & $113(53.6)$ & $54(60.0)$ & 0.305 & $192(61.5)$ & $149(60.3)$ & $43(66.2)$ & 0.392 \\
\hline $\begin{array}{l}\text { Periampullary } \\
\text { diverticulum }\end{array}$ & $104(34.6)$ & 75 (35.5) & $29(32.2)$ & 0.580 & $95(30.4)$ & $82(33.2)$ & $13(20.0)$ & $0.040 *$ \\
\hline Ampulla & & & & $0.000^{*}$ & & & & $0.000 *$ \\
\hline configurations & $64(21.3)$ & $64(30.3)$ & $0(0.0)$ & & $75(24.0)$ & $75(30.4)$ & $0(0.0)$ & \\
\hline Non-prominent & $205(68.1)$ & $136(64.5)$ & 69 (76.7) & & $198(63.5)$ & $157(63.6)$ & $41(63.1)$ & \\
\hline Prominent & $25(8.3)$ & $8(3.8)$ & 17 (18.9) & & $25(8.0)$ & $11(4.5)$ & $14(21.5)$ & \\
\hline Bulging & $3(1.0)$ & $2(0.9)$ & $1(1.1)$ & & $11(3.5)$ & $3(1.2)$ & $8(12.3)$ & \\
\hline $\begin{array}{l}\text { Distorted } \\
\text { Hook-nose } \\
\text { shape }\end{array}$ & $4(1.3)$ & $1(0.5)$ & $3(3.3)$ & & $3(1.0)$ & $1(0.4)$ & $2(3.1)$ & \\
\hline Malignancy & $110(36.5)$ & 77 (36.5) & $33(36.7)$ & 0.977 & $111(35.6)$ & $87(35.2)$ & $24(36.9)$ & 0.800 \\
\hline $\begin{array}{c}\text { Benign } \\
\text { diseases }\end{array}$ & $191(63.5)$ & $134(63.5)$ & $57(63.3)$ & & $201(64.4)$ & $160(64.8)$ & $41(63.1)$ & \\
\hline
\end{tabular}

$* p$ value $<0.05$

Table 3. Compared results between the expert and beginner endoscopists in each primary cannulation technique. 


\begin{tabular}{|c|c|c|c|c|c|c|}
\hline & \multicolumn{3}{|c|}{ Conventional technique with sphincterotomy } & \multicolumn{3}{|c|}{$\mathrm{NKF}$} \\
\hline & $\begin{array}{c}\text { Expert } \\
(\mathrm{n}=211)\end{array}$ & $\begin{array}{c}\text { Beginner } \\
(\mathrm{n}=247)\end{array}$ & $\mathrm{P}$ value & $\begin{array}{l}\text { Expert } \\
(\mathrm{n}=90)\end{array}$ & $\begin{array}{c}\text { Beginner } \\
(\mathrm{n}=65)\end{array}$ & $\mathrm{P}$ value \\
\hline Success rate, initially & $127 / 211(60.2)$ & $161 / 247(65.2)$ & 0.271 & $88 / 90(97.8)$ & $61 / 65(93.8)$ & 0.203 \\
\hline Success rate, finally & $207 / 211(98.1)$ & $236 / 247(95.5)$ & 0.126 & $89 / 90(98.9)$ & $62 / 65(95.4)$ & 0.208 \\
\hline Cannulation time (min) & $7.2 \pm 7.3$ & $6.6 \pm 7.2$ & 0.365 & $5.1 \pm 5.7$ & $5.7 \pm 4.5$ & 0.494 \\
\hline Total Procedure time (min) & $19.4 \pm 11.0$ & $18.2 \pm 10.1$ & 0.270 & $15.8 \pm 10.3$ & $14.5 \pm 7.6$ & 0.403 \\
\hline Post-ERCP pancreatitis & $12(5.7)$ & $28(11.3)$ & 0.033* & $1(1.1)$ & $2(3.1)$ & 0.384 \\
\hline Hyperamylasemia & $31(14.7)$ & $42(17.0)$ & 0.501 & $5(5.6)$ & $6(9.2)$ & 0.383 \\
\hline Bleeding & $3(1.4)$ & $8(3.2)$ & 0.206 & $2(2.2)$ & $4(6.2)$ & 0.213 \\
\hline
\end{tabular}

$* p$ value $<0.05$

Table 4. Compared results between the conventional technique with sphincterotomy and NKF groups in cases performed by the expert endoscopist.

\begin{tabular}{lcccc}
\hline & Total & Conventional technique with sphincterotomy & NKF & $P$ value \\
& $\mathrm{N}=301,(\%)$ & $\mathrm{N}=211,(\%)$ & $\mathrm{N}=90,(\%)$ & $88 / 90(97.8)$ \\
Success rate, initially & $215 / 301(71.4)$ & $127 / 211(60.2)$ & $89 / 90(98.9)$ & 0.579 \\
Success rate, finally & $297 / 301(98.7)$ & $207 / 211(98.1)$ & $5.1 \pm 5.7$ & $0.016^{*}$ \\
Cannulation time (min) & $6.5 \pm 6.9$ & $7.2 \pm 7.3$ & $15.8 \pm 10.3$ & $0.009^{*}$ \\
Total Procedure time (min) & $18.3 \pm 10.9$ & $19.4 \pm 11.0$ & $1(1.1)$ & 0.074 \\
Post-ERCP pancreatitis & $13(4.3)$ & $12(5.7)$ & $5(5.6)$ & $0.025^{*}$ \\
Hyperamylasemia & $36(12.0)$ & $31(14.7)$ & $2(2.2)$ & 0.620 \\
Bleeding & $5(1.7)$ & $3(1.4)$ & &
\end{tabular}

$* p$ value $<0.05$

Table 5. Compared results from successful procedures between the conventional technique with sphincterotomy and NKF groups in cases performed by the expert endoscopist. 


\begin{tabular}{|c|c|c|c|c|}
\hline & $\begin{array}{c}\text { Total } \\
\mathrm{N}=215,(\%)\end{array}$ & $\begin{array}{l}\text { Successful conventional technique with sphincterotomy } \\
\qquad \mathrm{N}=127,(\%)\end{array}$ & $\begin{array}{l}\text { Successful NKF } \\
\qquad \mathrm{N}=88,(\%)\end{array}$ & $P$ value \\
\hline Cannulation time (min) & $4.4 \pm 5.3$ & $3.9 \pm 4.8$ & $5.0 \pm 5.7$ & 0.120 \\
\hline Total Procedure time (min) & $15.7 \pm 9.2$ & $15.7 \pm 8.2$ & $15.8 \pm 10.4$ & 0.958 \\
\hline Post-ERCP pancreatitis & $10(4.7)$ & $9(7.1)$ & $1(1.1)$ & $0.042 *$ \\
\hline Hyperamylasemia & $24(11.2)$ & $19(15.0)$ & $5(5.7)$ & $0.026^{*}$ \\
\hline Bleeding & $4(1.9)$ & $2(1.6)$ & $2(2.3)$ & 0.542 \\
\hline
\end{tabular}

$* p$ value $<0.05$

Table 6. Clinical factors associated with post ERCP pancreatitis in conventional technique with sphincterotomy and NKF group

\begin{tabular}{|c|c|c|c|c|c|c|c|c|c|c|}
\hline & \multicolumn{5}{|c|}{ Conventional technique with sphincterotomy } & \multicolumn{5}{|c|}{ NKF } \\
\hline & \multirow{2}{*}{$\begin{array}{l}\text { Total } \\
\mathrm{N}=458 \text {, } \\
(\%)\end{array}$} & \multirow{2}{*}{$\begin{array}{l}\text { With } \\
\text { PEP } \\
\mathrm{N}=40 \text {, } \\
(\%)\end{array}$} & \multirow{2}{*}{$\begin{array}{l}\text { Without } \\
\text { PEP } \\
\mathrm{N}=418 \text {, } \\
(\%)\end{array}$} & \multicolumn{2}{|l|}{ P-value } & \multirow{2}{*}{$\begin{array}{l}\text { Total } \\
\mathrm{N}=155, \\
(\%)\end{array}$} & \multirow{2}{*}{$\begin{array}{l}\text { With } \\
\text { PEP } \\
\mathrm{N}=3, \\
(\%)\end{array}$} & \multirow{2}{*}{$\begin{array}{l}\text { Without } \\
\text { PEP } \\
\mathrm{N}=152 \text {, } \\
(\%)\end{array}$} & \multicolumn{2}{|l|}{ P-value } \\
\hline & & & & Univariable & multivariable & & & & univariable & multivariable \\
\hline Age (years) & $\begin{array}{c}67.5 \quad \pm \\
13.0\end{array}$ & $\begin{array}{l}67.8 \pm \\
13.8\end{array}$ & $\begin{array}{c}67.5 \quad \pm \\
13.0\end{array}$ & 0.901 & - & $\begin{array}{c}65.3 \quad \pm \\
15.6\end{array}$ & $\begin{array}{r}64.7 \\
\pm 7.6\end{array}$ & $\begin{array}{cc}65.3 & \pm \\
15.7 & \end{array}$ & 0.942 & - \\
\hline Male (\%) & $\begin{array}{c}262 \\
(57.2)\end{array}$ & $\begin{array}{c}20 \\
(50.0)\end{array}$ & $\begin{array}{c}242 \\
(57.9)\end{array}$ & 0.336 & - & $\begin{array}{c}97 \\
(62.6)\end{array}$ & $\begin{array}{c}1 \\
(33.3)\end{array}$ & $\begin{array}{c}96 \\
(63.2)\end{array}$ & 0.294 & - \\
\hline $\begin{array}{l}\text { Periampullary } \\
\text { diverticulum }\end{array}$ & $\begin{array}{c}157 \\
(34.3)\end{array}$ & $\begin{array}{c}12 \\
(30.0)\end{array}$ & $\begin{array}{c}145 \\
(34.7)\end{array}$ & 0.552 & - & $\begin{array}{c}42 \\
(27.1)\end{array}$ & $\begin{array}{c}1 \\
(33.3)\end{array}$ & $\begin{array}{c}41 \\
(27.0)\end{array}$ & 0.808 & - \\
\hline $\begin{array}{l}\text { Bulging / } \\
\text { distorted } \\
\text { ampulla }\end{array}$ & $24(5.2)$ & $\begin{array}{c}4 \\
(10.0)\end{array}$ & $20(4.8)$ & 0.158 & 0.302 & $\begin{array}{c}40 \\
(25.8)\end{array}$ & $0(0)$ & $\begin{array}{c}40 \\
(26.3)\end{array}$ & 0.305 & - \\
\hline Malignancy & $\begin{array}{c}164 \\
(35.8)\end{array}$ & $\begin{array}{c}15 \\
(37.5)\end{array}$ & $\begin{array}{c}149 \\
(35.6)\end{array}$ & 0.816 & - & $\begin{array}{c}57 \\
(36.8)\end{array}$ & $\begin{array}{c}2 \\
(66.7)\end{array}$ & $\begin{array}{c}55 \\
(36.2)\end{array}$ & 0.281 & - \\
\hline $\begin{array}{c}\text { Benign } \\
\text { diseases }\end{array}$ & $\begin{array}{c}294 \\
(64.2)\end{array}$ & $\begin{array}{c}25 \\
(62.5)\end{array}$ & $\begin{array}{c}269 \\
(64.4)\end{array}$ & - & - & $\begin{array}{c}98 \\
(63.2)\end{array}$ & $\begin{array}{c}1 \\
(33.3)\end{array}$ & $\begin{array}{c}97 \\
(63.8)\end{array}$ & - & - \\
\hline $\begin{array}{c}\text { Beginner } \\
\text { endoscopist }\end{array}$ & $\begin{array}{c}247 \\
(53.9)\end{array}$ & $\begin{array}{c}28 \\
(70.0)\end{array}$ & $\begin{array}{c}219 \\
(52.4)\end{array}$ & $0.033 *$ & $0.030 *$ & $\begin{array}{c}65 \\
(41.9)\end{array}$ & $\begin{array}{c}2 \\
(66.7)\end{array}$ & $\begin{array}{c}63 \\
(41.4)\end{array}$ & 0.384 & 0.112 \\
\hline $\begin{array}{l}\text { Pancreatic } \\
\text { duct stent }\end{array}$ & $\begin{array}{c}89 \\
(19.4)\end{array}$ & $\begin{array}{c}4 \\
(10.0)\end{array}$ & $\begin{array}{c}85 \\
(20.3)\end{array}$ & 0.115 & 0.469 & $0(0.0)$ & $\begin{array}{c}0 \\
(0.0)\end{array}$ & $0(0.0)$ & - & - \\
\hline $\begin{array}{l}\text { Cannulation } \\
\text { time (min) }\end{array}$ & $\begin{array}{cc}6.9 & \pm \\
7.2 & \end{array}$ & $\begin{array}{c}8.4 \quad \pm \\
6.5\end{array}$ & $\begin{array}{c}6.7 \\
\pm 7.3\end{array}$ & 0.152 & $0.005^{*}$ & $\begin{array}{l}5.3 \quad \pm \\
5.2\end{array}$ & $\begin{array}{r}15.7 \\
\pm 7.0\end{array}$ & $\begin{array}{c}5.1 \quad \pm \\
5.0\end{array}$ & $0.000 *$ & 0.978 \\
\hline $\begin{array}{l}\text { Total } \\
\text { Procedure } \\
\text { time (min) }\end{array}$ & $\begin{array}{c}18.8 \pm \\
10.5\end{array}$ & $\begin{array}{l}21.2 \pm \\
9.7\end{array}$ & $\begin{array}{c}18.6 \pm \\
10.6\end{array}$ & 0.138 & 0.380 & $\begin{array}{l}15.3 \pm \\
9.3\end{array}$ & $\begin{array}{l}34.7 \\
\pm \\
13.6\end{array}$ & $\begin{array}{l}14.8 \pm \\
8.8\end{array}$ & $0.000 *$ & $0.009 *$ \\
\hline
\end{tabular}

\section{Figures}



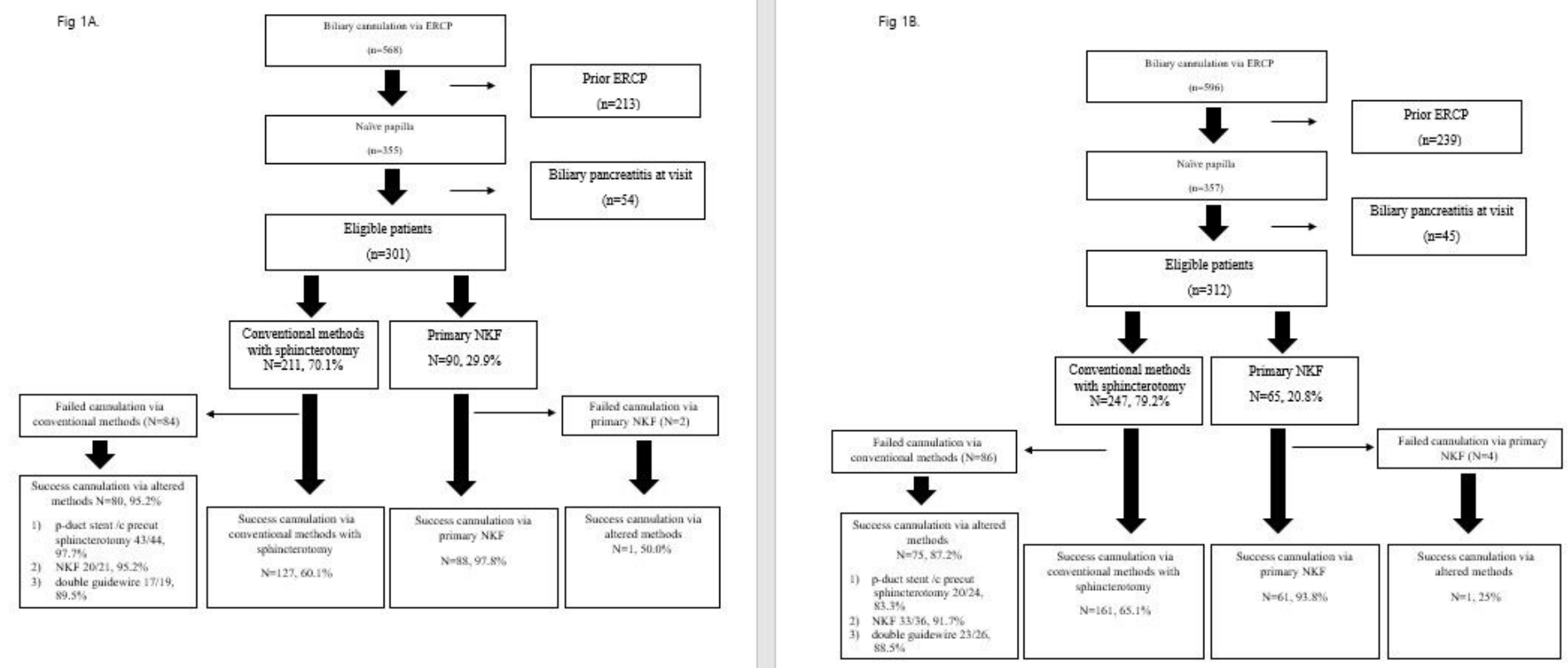

Figure 1

Fig 1A. Study flow chart.(Expert endoscopist) Fig 1B. Study flow chart.(Beginner endoscopist) 

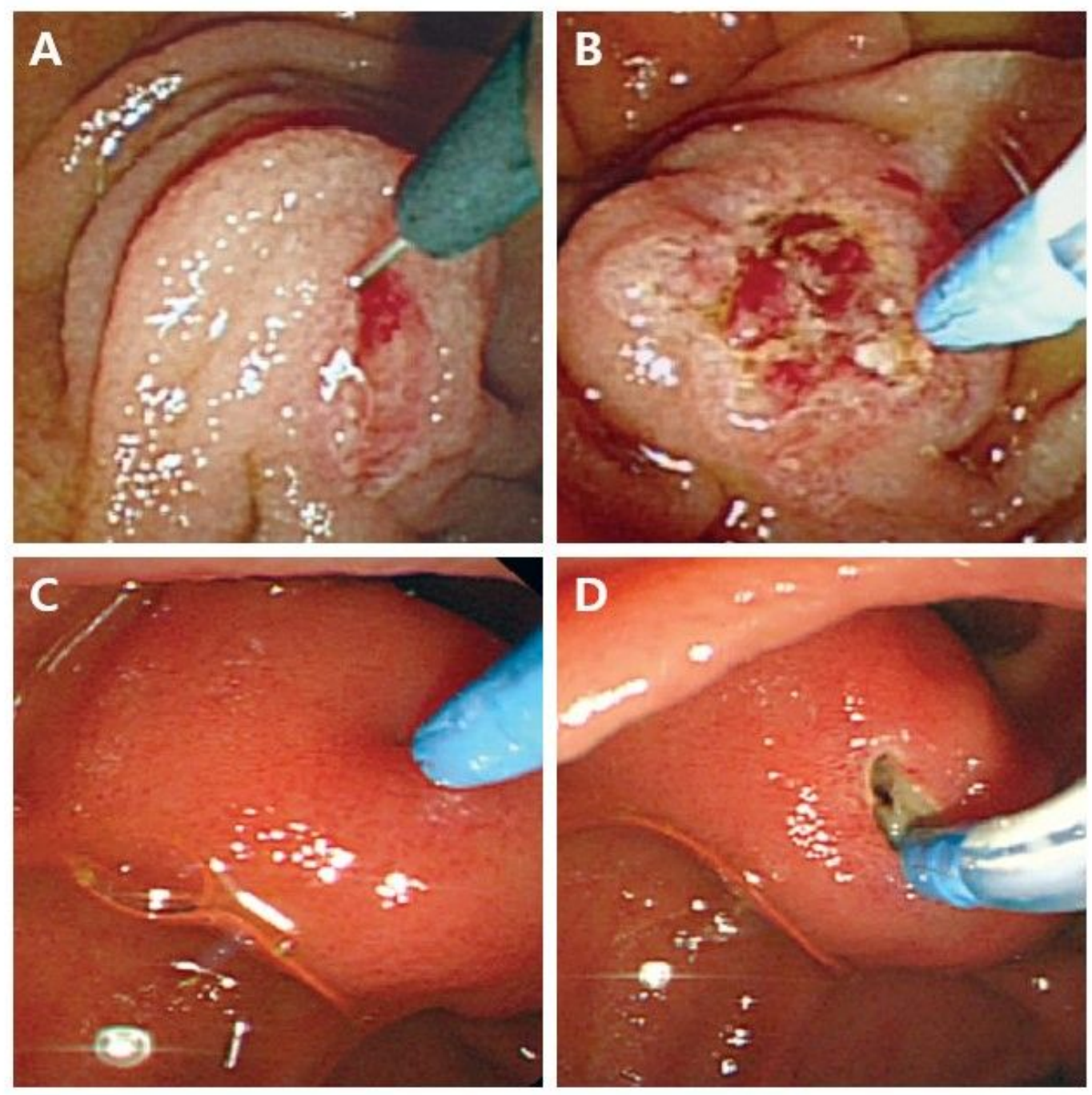

\section{Figure 2}

Comparison of precut sphincterotomy and NKF[12] A. The needle is placed at the orifice of the ampulla B. Precutting was performed with slight upward tension $\mathrm{C}$. Mucosal incision at the maximal bulging point of the papillary roof of the ampulla D. Incision at the oral side of the bile duct at the 11-12 o'clock position relative to the ampulla of Vater 